Archived version from NCDOCKS Institutional Repository http://libres.uncg.edu/ir/asu/

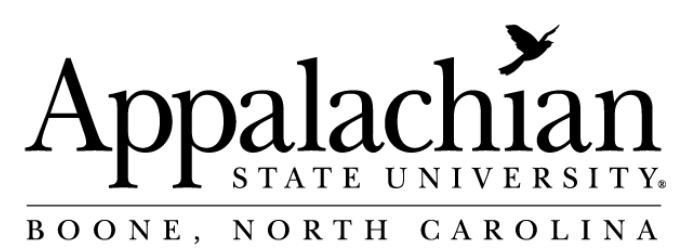

\title{
Handling Student Excuses
}

\author{
By: Linda Johanson
}

No Abstract

Johanson, Linda (2011) "Handling Student Excuses". Journal of Christian Nursing, 28(1), 49. Version of record available from Elsevier. [ISSN: 0743-2550], [DOI: DOI: 10.1097/CNJ.0b013e3181fefc3f]. 


\section{Handling Student Excuses}

0

ne inevitable aspect of being a nurse educator involves dealing with excuses from students. Students have excuses for being late, for missing class, for forgetting a procedure, and on and on. And while all excuses are not invalid, they do present a particular dilemma for nurse educators.

The problem that excuses create for educators is primarily one of maintaining equity. An environment where students sense that one excuse is more acceptable than another may inadvertently encourage lying. Educators may feel the need to rate the quality of excuses or decide on their truthfulness when employing sanctions.

The perception of unfairness associated with consequences can create a culture of unrest among students that may interfere with learning. Both students and faculty become distracted with tracking and comparing situations where excuses and consequences occurred. The learning environment can become tense, competitive, and argumentative.

Nurse educators are in a position to create positive learning environments where students are not expected to make excuses for unacceptable behavior. This type of culture eliminates the need to judge the veracity and quality of excuses. Focus instead on desired behavior. This is accomplished by having clear, written policies that outline expected behaviors and the consequences for deviations. For example, if being late to class is not desirable, the syllabus might indicate that a one point deduction will result for in-class work for each minute a student is late. Do not expect students to explain why they are late; it should be immaterial. Apply policies uniformly and consistently. Be transparent in dealing with excuses from students to avoid any perception of unfairness.

Another suggestion is to make sure that the consequences applied for unacceptable behaviors are appropriate. For example, a zero-tolerance policy for missed clinical with the consequence of a paid, required makeup day is unbalanced. Because it's a huge penalty, under this policy a legitimately ill student might be inclined to lie to avoid the fine. A better strategy could be to build an extra day into the schedule and allow at least one missed day without consequence.

In Luke 14:16-24 Jesus tells the story of a man who gave a big dinner and invited many people. Those invited made excuses about why they could not attend. The account indicates that this excuse-making behavior angered the head of the household. Others were invited to the celebration in place of those who gave excuses, and those who gave excuses missed out on an opportunity to enter the Kingdom of God. What do students miss who make excuses? As educators we want to encourage students to take advantage of opportunities available in nursing school rather than making excuses, and it is up to us to create effective ways to encourage this.

Finally, the personal behavior of Christian nurse educators is applicable. Educators should model the behaviors desired in students and should never make excuses for issues with their work or behavior. Christian educators can pray for students as well. Students come from a variety of backgrounds, and there are many reasons why they may feel the need to make excuses. Sometimes by understanding students' backgrounds, we can help them grow and realize they don't need to make excuses. Although teachers may not always condone the behavior of students, it's important to convey an attitude of care and support and the desire to help students succeed. 